\title{
Impact Of Graduate Program Delivery Models On Teacher Candidates' Success And Perception
}

Mitra Fallahi, (Email: fallahi@sxu.edu), Saint Xavier University Beverly Gulley, Saint Xavier University

\begin{abstract}
In recent years the demographics of individuals pursuing teacher certification has changed. Many individuals with a bachelor's degree who are interested in a change of career pursue teaching after receiving a college degree in areas other than teacher certification. Institutions of higher education have made a distinction between their traditional 18 to 22 year old college students and those "career changers" seeking teacher certification with a completed degree, life experience, and sometimes even experience in the classroom as a substitute teacher or teacher's aid, or even a teacher. There are graduate programs designed for these post baccalaureate candidates leading to a degree and certification. In an effort to increase the retention of these non-traditional students and to ensure their success in achieving their goal of becoming a teacher, institutions of higher education have adopted different models of program delivery for nontraditional post-baccalaureate students. One such option of is cohort models in higher education. On some campuses candidates have the option of pursuing their education in a cohort model or traditional model. Does the model of program delivery make a difference in candidates' success in achieving their goal of becoming a teacher? Does the model of delivery impact candidates' perception about their educational experience? The questions investigated in the research are whether or not there is a difference in performance of students who complete the program in cohort model with those completing the program in traditional model and whether there is a difference of perception of the program between the two groups completing the program.
\end{abstract}

\section{INTRODUCTION}

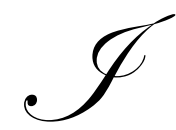

nstitutions of higher education have adopted different methods of course delivery in recent years. Changes in delivering graduate programs in non-traditional models such as cohort and on-line models have become inevitable as higher education has become more and more a necessity of life especially in industrialized countries, instead of a privilege of the elite and those with great aspirations for advancement of knowledge and intellect. This necessity of higher education as a medium to enhance, improve, or change paths of life has lead universities to align their programs with the needs of individuals in the society and their fast pace of life.

In recent years two models of program delivery have become prevalent in higher education, programs offered in cohort or on line. The cohort model in this study refers to the forms of program delivery where groups of students sign up for a program and take a prescribed sequence of courses at a pre-determined time and schedule. The more recent and fast growing model of program or course delivery is the offering of the programs partially or fully on line. These models of delivery are specially becoming prevalent for graduate programs. 


\section{RATIONALE FOR SELECTING NON-TRADITIONAL MODELS}

\section{Students' Perspective}

There are two groups of individuals pursuing advanced or post-baccalaureate education in teacher education programs. The first group includes teachers or school personnel who choose to seek an advanced degree with or without additional certification. The second group includes individuals who have a bachelors' degree but do not have the coursework and credentials (certification) required for teaching, or "career changers." Reasons for seeking a Masters degree in education vary for these groups. Advanced degrees are specifically becoming popular among teachers or school personnel for several reasons. First, teachers feel the need for additional knowledge and enhancement of their education as they enter the classroom and face the challenges and needs of everyday teaching. Second, it is almost impossible to find a state in the country where a certified teacher would not be required to continue his or her education to maintain the certification status. Third, with the No Child Left Behind Act, districts and school administrators are required to fill teaching and personnel positions with individuals who are certified and have specialization in the area in which they are working. As a result districts encourage their faculty to pursue certification in new areas such as reading specialists or special education teachers. Last but not least, pursuing an advance degree is an incentive for teachers, as it constitutes an increase in salary.

Career changers or individuals without appropriate teaching credentials prefer to fulfill their certification requirements in post-baccalaureate programs that preferably lead to an advanced degree. Pursuing a certification program at the graduate level gives them the opportunity to seek an advanced degree simultaneously and attend the program with individuals closer to their age range and life experiences.

Individuals of non-traditional age typically have numerous commitments in life. A full time job, a family, and responsibilities toward the elders and extended family are a few of the common involvements that individuals seeking graduate studies report to have (Fallahi, Gulley, 2003). As a result, pursuing a graduate program of study can seem impossible for these students. They are seeking a program that ensures that they reach their goal in a short period of time and in a fast pace. They choose non-traditional programs such as programs offered in cohort models or on-line in an effort to pursuit their educational goals (O'Lawrence, 2006).

\section{Institutions' Perspective}

In the United States most institutions of higher education are affected by the revenue generated by student tuition. The needs of graduate students stated above can be critical when universities consider models of program delivery. Historically, delivering graduate programs in a cohort model was more prevalent than offering programs "on-line." However, in recent years with the advent of technology and the advancements in using the Internet as an interactive and educational medium on one hand and the demand from prospective students on the other hand, universities have moved to adopting the on-line delivery model, sometimes despite resistance from within. Reasons for an institution to adopt a non-traditional model of program delivery vary but in general, increasing retention, predictability for better budgetary and staff projections, and sustainability of programming are among reasons for institutions to adopt cohort models of delivery (Fallahi, Gulley, 2003). Offering programs on line increases the availability of the programs to individuals at a national level, and reduces the costs, both desirable options for institutions of higher education.

\section{CHARACTERISTICS OF NON-TRADITIONAL MODELS AND THE FOCUS OF THE STUDY}

Students described the most desirable characteristics of cohort models as certainty, the pre-determined schedule, and the sense of belonging to a group (Fallahi, Gulley, 2003). While we realized through research that cohort program are popular and their appeal might contribute to students' success in completing the program, this investigation focused on comparing students' academic performance and perceptions of their experience and whether or not the model of delivery contribute to students' success. The focus of this study was to compare the perception and the success rate of students in a cohort model to those of students enrolled in a traditional model at the same institution. 


\section{REVIEW OF LITERATURE}

Institutions of higher education offer their programs in cohort models on their campuses or in settings off their campuses. The School of Education at Saint Xavier University has offered most of its graduate programs at its two campuses in a cohort model since 1999 (Fallahi, Gulley, 2003).

Traditionally individuals interested in pursuing an advanced degree in higher education would apply to a program and upon admission would be assigned to an advisor who assisted them in signing up for classes as offered and completing the requirements for the program. This process worked well for most graduate students at that time. Gradually the demographics of individuals interested in advanced degrees changed to include mostly individuals who chose to pursue a graduate degree as they were raising a family, having a career, or both. Nebist (2001) describes characteristics of adult learners and states that cohort models developed for experienced adult learners must include self-directed and transformational learning, critical reflection. Transformational learning is a process by which individuals examine existing experiences and use the acquired knowledge to develop new information and plans of action. Fallahi and Gulley (2004) describe the cohort model as a program in which "a group of students are admitted to a program of study and follow a prescribed schedule together" (page 1). Cohort models vary from institution to institution and from program to program. One of the most prominent characteristics of cohort models is their pace. Programs delivered in a cohort model take away some choices in selecting classes in an exchange for direction and certainty. In the same research Fallahi and Gulley (2004) found that students completing master degrees in their graduate programs in education stated an awareness of the schedule as the number one most important aspect of their choosing the cohort model.

Cunningham (1996) describes cohort programs as successful in recruiting marginalized persons for doctoral programs. In traditional models of delivering doctoral programs, only $16 \%$ of the student body was marginalized compared to $64 \%$ in a doctoral program offered in cohort model. Hatley and others (1996) state that their research on cohort programs in educational administration conclude that the cohort model had a positive impact on students' cognitive growth and professional development. Gilley et al. describe characteristics of the cohort model and discuss how a cohort model that can be conducive to learning and developing a sense of community. Shoho and Martin (1999) investigated the perception of alienation among alternatively and traditionally certified teachers. Alternatively certified teachers participated in a cohort program, and the traditionally certified teachers did not. Researchers found that alternatively certified teachers were significantly less isolated than traditionally certified teachers.

\section{METHODOLOGY}

A survey questionnaire was mailed to graduate students enrolled in the graduate education programs. The survey asked students about their experience and how they perceived their teacher education preparation. Responding to the survey was voluntary and the participants remained anonymous, unless they were interested in participating in focus group discussions. Students who were interested in focus group discussions were invited on campus to participate. Students who completed the survey were either in a cohort or traditional program. Those who attended the non-traditional program were familiar with the cohort programs because they had taken a course or two with the cohort groups or the cohort model was described to them. Cohort students were familiar with the traditional model mostly through their undergraduate education.

In addition to surveying students, the results of state tests for certification was used to compare students' performance since they had graduated from the same program delivered in either the cohort or the traditional model. We offer graduate programs leading to Master of Arts degree in education with certification in elementary education or secondary education in both cohort and traditional models. It is the policy of the institution to verify that every teacher candidate has passed the state certification tests as required by the Illinois State Board of Education and the State of Illinois prior to entitlement for certification. As a result there was access to all state certification test results. Finally, we incorporated the input of Graduate Admission Office who recruits students for the graduate programs. 


\section{ANALYSIS OF DATA}

\section{State Tests}

Graduate students in the two graduate programs leading to a Masters of Arts degree with certification in either elementary education or secondary education have to take three tests that are required by the Illinois State Board of Education. These tests include a Basic Skills Test, a Content-Area Test, and an Assessment of Professional Teaching Test. The results of students' performance on each test are shared with the institution from which the student is receiving his or her education. A review of tests taken over the last five years indicated that there was no difference between the students' performance on state administered tests whether they completed the program in the cohort or traditional model. A small percentage of students did not pass the test the first time. The number of students pursuing certification to teach at the secondary level was almost equal in the two different models of delivery, cohort or traditional. The number of graduate students in the elementary education program in the cohort model was significantly higher than those in traditional model.

\section{The Survey}

The survey included primary questions:

1. What were the strengths of the program?

2. Were they prepared for the state tests and their goal of becoming a teacher at the elementary or secondary levels?

3. Based on their experience with the two models of delivery, which model did they prefer?

Six additional questions focused on the students' status in the program.

\section{Survey Results}

The results of the survey indicated that all graduate students, whether enrolled in cohort or traditional model, identified the faculty as the most positive factor in their academic experience. Cohort students found characteristics of the cohort model such as class size, students' collaboration, and the scheduling of cohort models a positive aspect of their experience. They repeatedly referred to the pre-planned schedule as "seeing the light at the end of the tunnel." Responses from students in the traditional model varied from their student teaching experience to the flexibility of the traditional model, and the availability of the coursework in a more relaxed format.

In response to the question about whether or not the program prepared them for the state test, and their goal of becoming a teacher, all cohort students replied that they felt that they were prepared. One student in the traditional model stated that he did not know because he had not taken the last test yet. Another traditional student responded "no."

The last question asked if they would choose the cohort or the traditional model as their preferred model of delivery if they had a chance to make the decision again. Every student was given a description of the cohort model. Thirteen respondents had taken coursework in both models regardless of their primary program delivery. All cohort students (fourteen students) stated that if they had to do it all over again, they would choose the cohort model. Six students in traditional the model said that they would have chosen the traditional model with one student stating flexibility as an advantage of the traditional model. Another student stated that he or she would have chosen either one of the models.

\section{Focus Group Discussions}

Fourteen students participated in three different focus groups. Focus groups were an open forum where students met with the researchers and other students and discussed their experiences and perceptions of the model of delivery. For the most part the students interacted with each other as the researchers recorded the conversations. An 
overall review of the notes revealed that students were pleased with their programs and reported positively about their decision to pursue certification and their experience with the graduate program. Results of the focus group discussions along with a summary of the survey is presented in the next section.

\section{Results Of The Focus Group Discussions}

Graduates and students currently enrolled in the program who participated in the study by completing the survey were invited to participate in focus group discussions. Overall, all graduates were pleased with their experience, with the faculty, and when applicable with their cohort groups.

- $\quad$ The cohort students considered the cohort experience positive because of: 1) working with, getting to know, and getting assistance from other cohort members; 2) benefiting from the experience of some cohort members who were practicing teachers; 3 ) having classes at the same time, i.e. Tuesday nights for the duration of the program; 4) good instructors; 5) smooth transitions throughout the program; 6) sequence and schedule of courses.

- Non-cohort students described their satisfaction with the program because of: good relations with instructors and knowledgeable instructors.

- $\quad$ All cohort students said that they preferred the cohort model.

- One traditional student preferred the traditional model and stated that she was a full time traditional student and took more than two courses for certification so that she could complete the program more quickly.

- When asked if they would recommend the program to others, they all that they already had.

- $\quad$ They were all pleased with their decision to change careers and stated that they loved their new profession of teaching.

- $\quad$ Several students mentioned that they came from a business career and they are pleased that they have expertise in different areas, although they prefer teaching.

- $\quad$ Overall, they all expressed very positive view of the faculty.

\section{Summary of Comments Received at the Admission Office}

The counselors of Graduate Admission Office routinely receive requests for cohort programs. A summery of their reports indicate that most prospective students seeking graduate education programs are familiar with the cohort concept and inquire if the program is offered in a cohort model. The counselors summarized prospective students reasons for inquiring about graduate programs as follows:

- $\quad$ Pre-determined schedule;

- $\quad$ Length of program;

- $\quad$ Completing more than one course per semester while going to class one night a week;

- $\quad$ Discounted tuition; and

- $\quad$ Small class size

\section{CONCLUSION}

Offering graduate programs in non-traditional models is a necessity for institutions of higher education. Graduate programs become increasingly necessary for teachers seeking advancement and individuals seeking teaching or teaching-related professions. Students and institutions alike are interested in committing to programs or delivery models that are encouraging and beneficial both to the students and the institutions. The cohort model is one form of non-traditional program delivery that seems to work well for the institutions and the students. In this study the majority of students chose the cohort model because it fits their busy schedules and reported positive perceptions about the cohort model. The model of delivery did not have an impact on the students' academic success. The overall perception of experience of the students who completed the program in the cohort model was positive. They stated that if they chose to continue their education toward an advanced certificate in another program they would consider a cohort program at the university. In conclusion, the cohort model does not change the academic experience or the curricular content of a graduate program, but based on students' perception they 
have a positive impact on students' social experience and their perceptions of their academic achievement in life. Students seek cohort models for certainty, convenience, and financial benefit. They leave the program with a positive social and academic experience.

\section{REFERENCES}

1. Cunningham, P. (1996). Ideological space makers: The need in graduate programs in adult education. ED 401415.

2. Fallahi, M. \& Gulley, B. (2003). Cohort groups in graduate education. Illinois Schools Journal.

3. Gilley, J. Levya-Gardner, B. Korth, S., Conbere, J. Gibson, S. Gilley, A. (2005). HRD cohort graduate programs: An approach to creating a sustainable learning community and developmental culture. ED 492288.

4. Hatley, R. et. al. (1996). Evaluating the design, implementing, and impact of a non-traditional cohort Ed. D. program in Educational Leadership and Policy Analysis.

5. Nebist, T. (2001). Extending graduate education to non-traditional learners. ED 452750.

6. O'Lawrence, H. (2006). The influence of Distance Learning on adult learner. Techniques: Connecting Education and Career. 81(5).

7. Shoho, A. \& Martin, N. (1999). A comparison of alienation among alternatively and traditionally certified teachers. Resources in Education, 34(11). ED 431707.

\section{NOTES}

